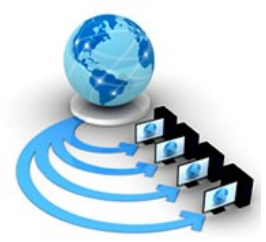

Volume 10, No. 1, January-February 2019

ISSN No. 0976-5697

International Journal of Advanced Research in Computer Science

RESEARCH PAPER

Available Online at www.ijarcs.info

\title{
COMPUTER - AIDED LEARNING SYSTEM FOR SAN JOSE ELEMENTARY SCHOOL G.M.A., CAVITE
}

\author{
Ma. Grace P. Miranda \\ College of Computer Studies \\ Trimex Colleges, Biñan, Laguna, Philippines \\ Ruel II Bergonio \\ College of Computer Studies \\ Trimex Colleges, Biñan, Laguna, Philippines
}

\author{
Ruel I Bergonio \\ College of Computer Studies \\ Trimex Colleges, Biñan, Laguna, Philippines \\ Jason T. Francisco \\ College of Computer Studies \\ Trimex Colleges, Biñan, Laguna, Philippines
}

\author{
Carlo A. Batitis \\ College of Computer Studies \\ Trimex Colleges, Biñan, Laguna, Philippines
}

\begin{abstract}
People use the computer; most of these are young people who love to play games on the computer. The computer does not only give information or search for an answer to our questions; it also provides pleasure that can be seen while using the computer, just like a television equipped with a keyboard and mouse. This study focuses on the utilization of computers as learning aide for children from grades 1-3, which includes those levels that have the minimal reading ability as the system is interactive and the graphical user interface suits the primary end users' needs. The system includes learning modules adapted to the school's curriculum and resources, educational games, learning assessments and function for generation of progress reports.
\end{abstract}

Keywords: computer-aided learning, CAI, educational game, e-learning, education

\section{INTRODUCTION}

Technology became more advanced and systematized with computers and electronics. It continuously evolves day-by-day and adapting in today is constantly changing the digital world. Children nowadays are using computers to play games especially children $7 \mathrm{yrs}$. Old and below, but most of them do not know how to read yet. This system was developed for them, as they use the computer, they also learn. According to the interviews made by the proponents, most of the students of the San Jose Elementary School are having difficulties in reading the English language. The researchers developed a program that is valuable and to help students how to pronounce and recite the alphabet. Besides from reading, the researchers added more learning modules according to the subjects of the user per grade level.

Based on research at the San Jose Elementary, the Grade 1-2 pupils are not very focused on teacher lessons, because of the noise of other learners and most of the pupils cannot understand the topic. Thus they cannot focus on the subject, and they are easily distracted while Grade 3 pupils are not fond of the conventional teaching methods anymore. Some pupils in grade 3 mostly prefer playing rather than attending their subjects. With this, the researchers came up with the solution for the mentioned issues; these are: a) developing a computer-aided learning system with interactive user interface, b) creating additional educational games for entertainment and learning, c) adding an assessment function to the system will help ensure the learning of students, and d) monitoring and keeping track of the learners' progress for the teachers.

Elaborating more on the functions and features of the project, the Computer-Aided Learning System for San Jose Elementary School is a stand-alone computer application comprised of three modules: student, teacher, and administrator, which are all required to log-in to the system for them to be able to use it. Other modules, include learning modules not only for reading and counting but also in other subjects depending on the grade level of the logged-in user (as for learning resources, these are available in several formats, e.g., digital storytelling, video, audio, animation, graphics, and text), assessment modules which can be updated from time to time, and progress report module for tracking student learning progress to help teachers in monitoring their students' learning capacity as they continue to acquire more knowledge and skills through the application. Moreover, the three mentioned accessibility roles could only use the app within the premises of San Jose Elementary School.

\section{LITERATURE SURVEY}

According to the Authors, this study is intended to address the issues of the learners' difficulties regarding class participation through Computer-Aided Learning. ${ }^{1]}$ 
Also, the Authors probed on the understanding capacity of the learners and developed this system with teaching modules by using interactive learning materials, ${ }^{[2]}$ digital storytelling ${ }^{[3]}$ and educational games. ${ }^{[4]}$

Furthermore, the Authors have added assessment tests or quizzes ${ }^{[5]}$ to evaluate the students' comprehensive and arithmetic skills.

The Authors have included in this study as well as the significance of monitoring and keeping track of the learners' progress. ${ }^{[6]}$

\section{DESIGN OF THE STUDY}

The interface of the program was designed to cater to the capabilities of its primary user, which in this case are the students, and to capture their attention thru entertaining but educational materials. To secure one's account, a user must have a username and password to $\log$ in.

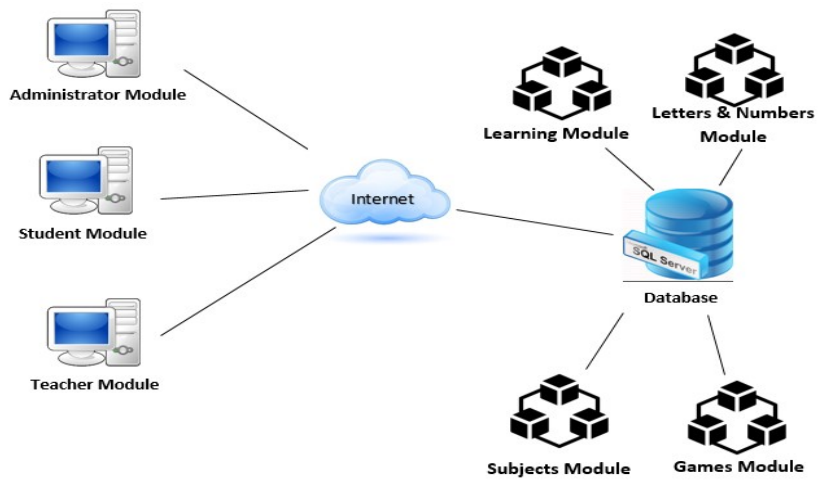

Figure 1. System Architecture

The three user modules: Admin, Student, and Teacher, need to connect to the internet to be able to login to the system since the database connection of the application is in the Cloud. After logging in, a Student account can access the following modules: Learning, Letters \& Numbers, Subjects, and Games. While the Teacher account can access the admin panel of the system where they input the learning materials, view their students per subject, and track their learning progress. Lastly, the Administrator account can add, edit and delete student and teacher accounts, courses, and learning materials; it can also view the development of the students.

\subsection{USE CASE DIAGRAM}

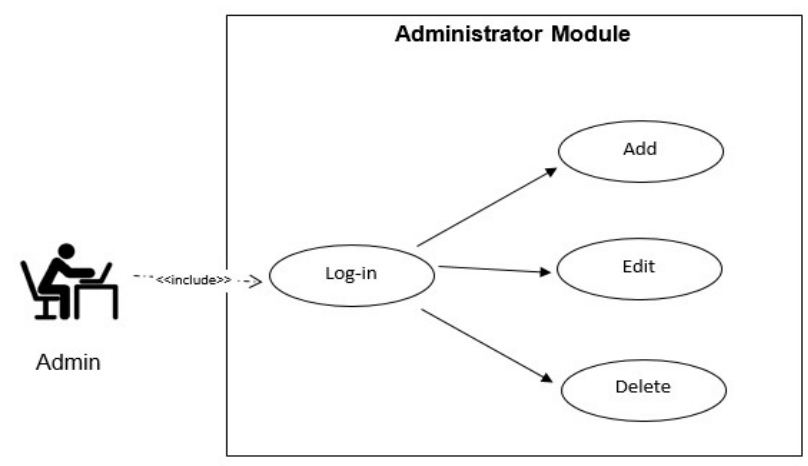

The figure shows that the administrator needs to log-in to do their task. He or she can manage questions, upload lesson video and administer lesson quiz, and only admin can add a Digital Storytelling video for the student and can manage teacher and student account, and only admin can manage student information.

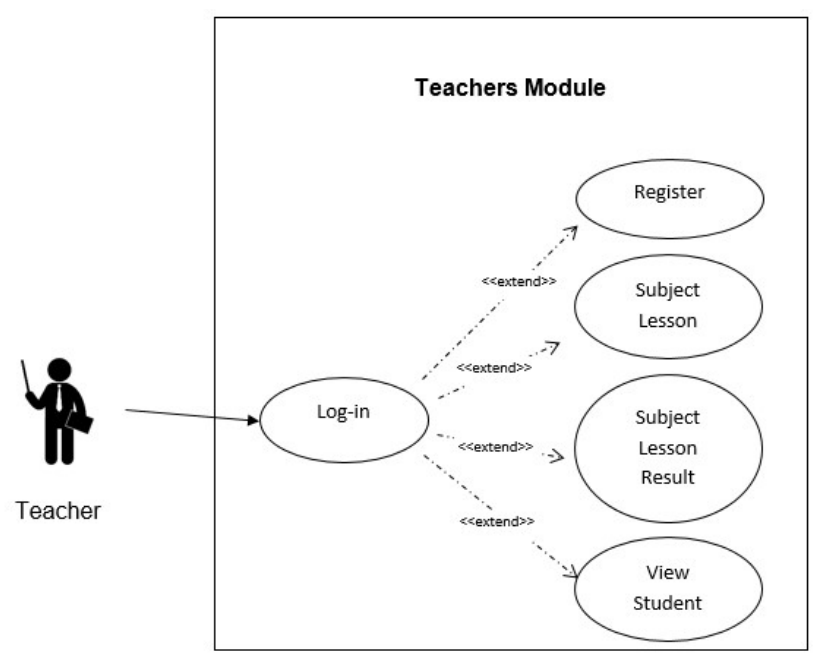

Figure 3. Use Case Diagram of Teachers Module

The figure shows that Teachers need to login to be able to use the system. If the user is a new teacher, then he/she needs to contact the administrator to register. The teacher can access the viewing of a student in specific grade level and section, and also viewing of subject lesson result or student progress. They can also add and edit assessment tests.

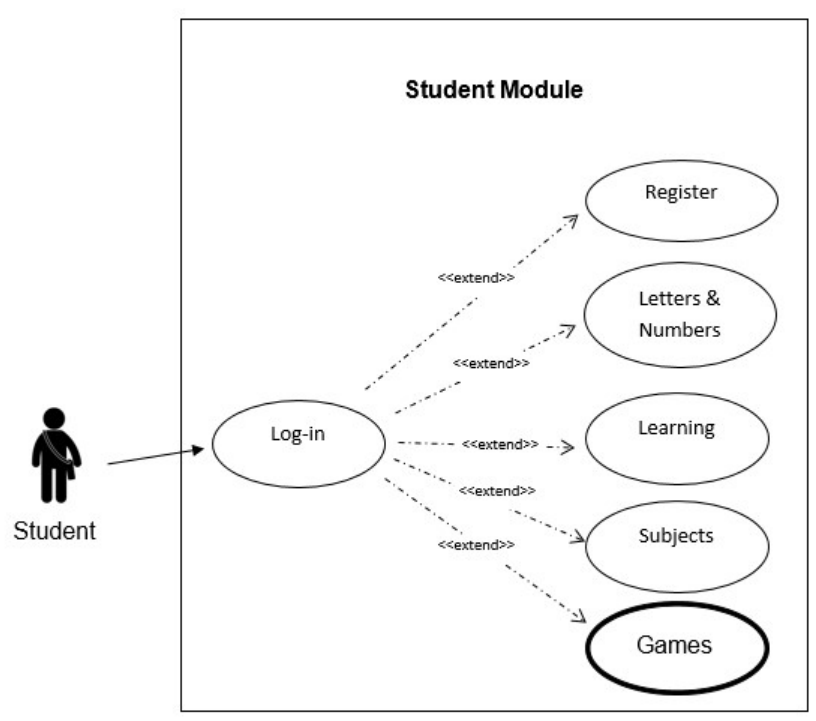

Figure 4. Use Case Diagram of Student Module

The user needs to $\log$ in and if the user is a new student, then need to contact the admin to register. They have access to the Letters \& Numbers module, Learning module, Subjects module and the Games module which is optional. 


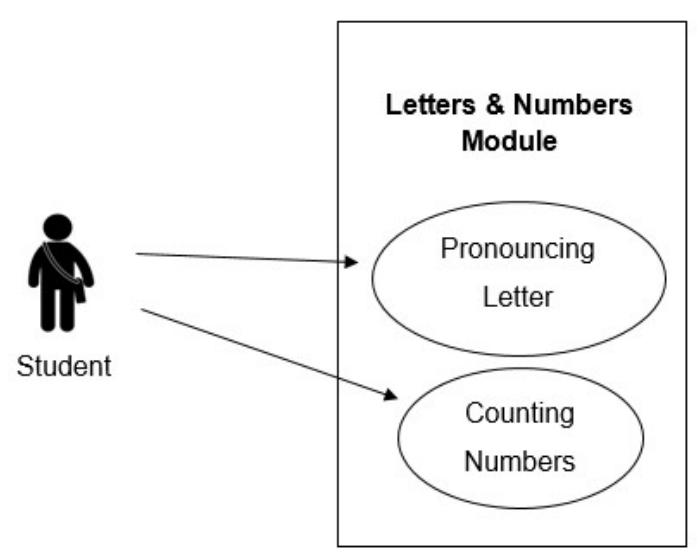

Figure 5. Use Case Diagram of Letters and Numbers Module

In this module, the student can learn how to pronounce letter and how to count numbers correctly by using interactive learning materials.

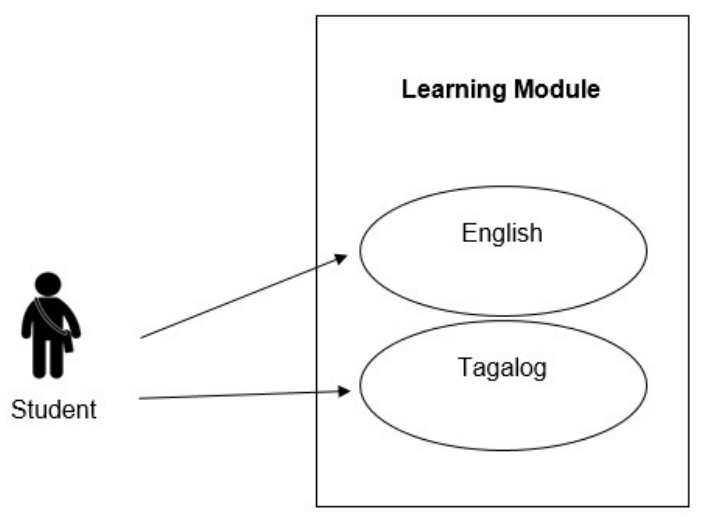

Figure 6. Use Case Diagram of Learning Module

In this Learning module, the student can learn English/Tagalog words through videos and Digital Storytelling, which is a video with a story or plot.

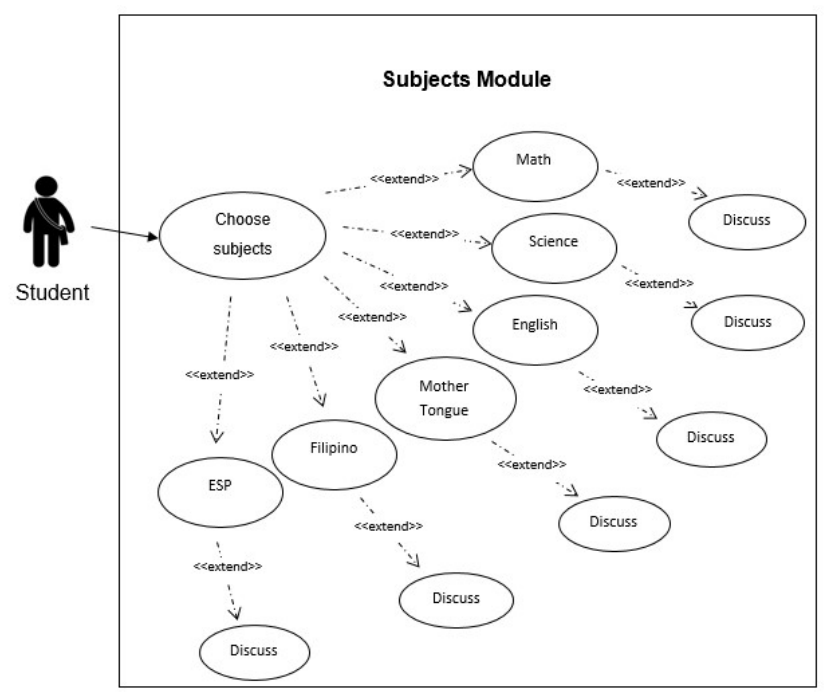

Figure 7. Use Case Diagram of Subjects Module
In this module, the learners can select the subject/s that they want to learn. The available subjects are Math, Science, English, Mother Tongue, Filipino, and ESP (Edukasyon sa Pagkatao). These subjects that will appear on the system depends on the grade level of the student since the curriculum for grade levels 1-3 are different per year.

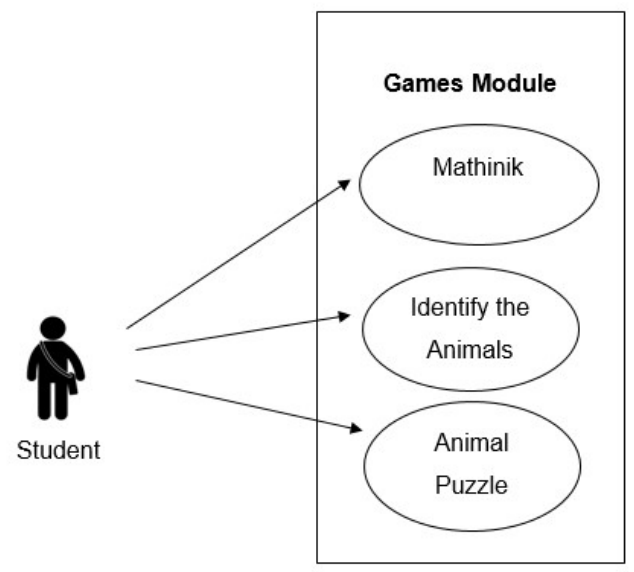

Figure 8. Use Case Diagram of Games Module

The student can play mind games like a) Identify the Animals wherein a player needs to select the right habitat based on the animal picture presented, b) Animal Puzzle which is a game that requires learners to answer simple math operations to remove the white box and identify the image, and lastly c) Mathinik which is a game where the player needs to solve math problems in addition, subtraction and multiplication.

\subsection{DATA FLOW DIAGRAM}

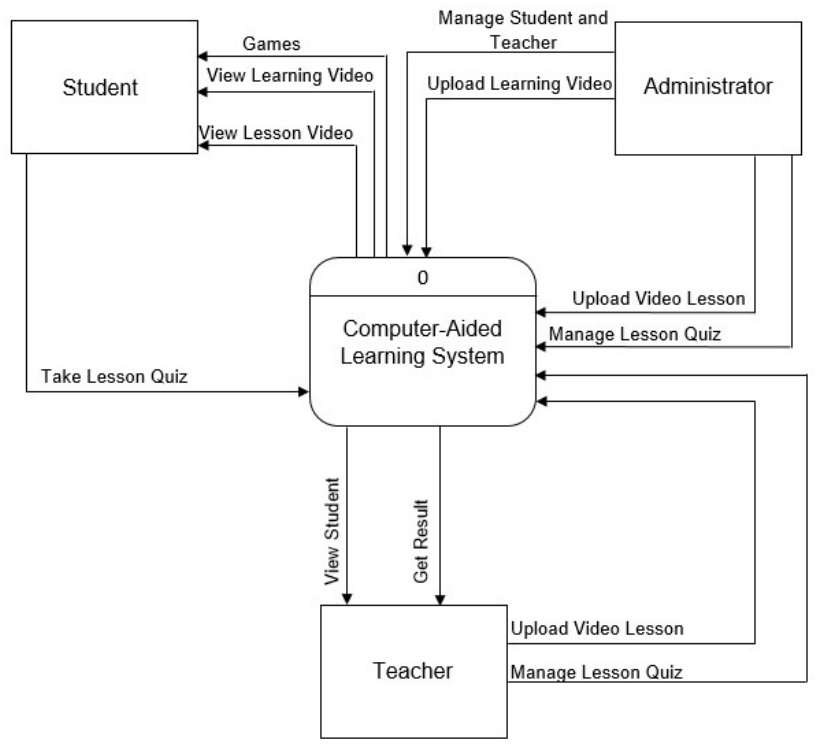

Figure 9. Context Diagram of Computer-Aided Learning System for San Jose Elementary School

The figure shows how the data travels and being manipulated throughout the whole system. The three external entities which have significant functions in the app are namely Student, Administrator, and Teacher. 


\section{RESULTS AND DISCUSSION}

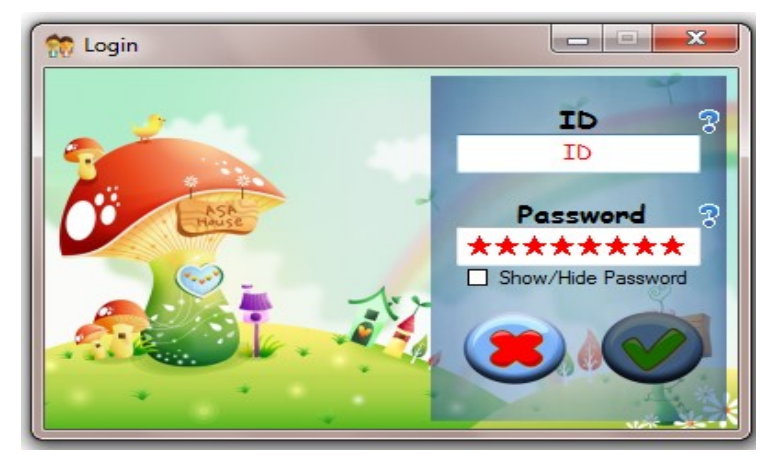

Figure 10. Login

The Login window, it contains child-friendly background music, and the system can recognize the user type of the person logging in, thus redirects him or her to the appropriate main window for either a student, teacher, or administrator.

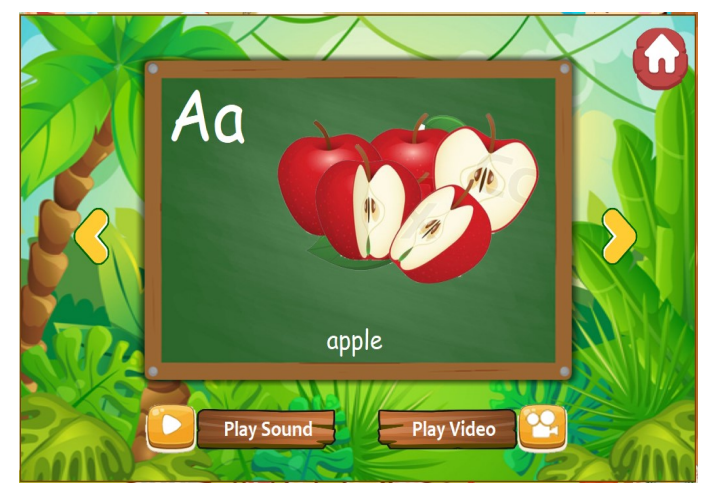

Figure 11. Learning Materials

The figure shows the available learning materials for the learners and this template is applied to all lessons in the system.

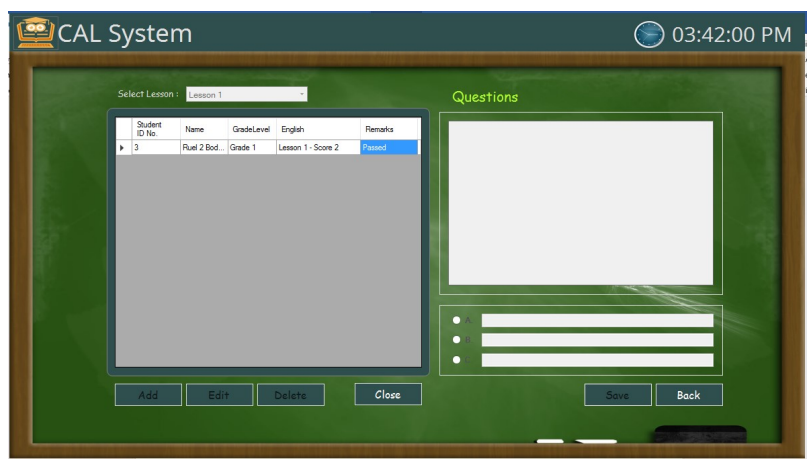

Figure 12. Assessment and Progress Report Window
The window shown above allows the teachers to add and edit assessments tests or quizzes and as well as view the learners' results.

\section{CONCLUSION}

The Computer - Aided Learning System will help not only its primary users who are the students but also the teachers. The students will be more technology inclined and be much more attentive than conventional teaching since the app was developed with interactive learning modules and educational games.

On the other hand, it will also lessen the workload of the teachers since the system not only can be an alternative to conventional teaching but also has functions for creating assessment tests and automatically records and keeps track of learners' results.

\section{RECOMMENDATIONS}

The researchers of the study further recommended the following:

1. Make the system available to mobile devices.

2. Make the system available not only for the primary grade levels (1-3) but the entire elementary grade levels, up to grade 6 .

3. To add more Educational Games for the students.

4. To add more features that will help the administrator, teachers, and students efficiently use the system.

\section{REFERENCES:}

[1] Arasteh, Draghici, and Mustea. "E-Learning System," 2014, 755.

[2] Rondon, S., F. C. Sassi, and C. F. De Andrade. "Computer Game-based and Traditional Learning Method: A Comparison Regarding Students' Knowledge Retention," 2013.

[3] Price, D. M., L. Strodtman, E. Brough, S. Lonn, and A. Luo. "Digital Storytelling: An Innovative Technological Approach to Nursing Education," 2015.

[4] Mackay, R. F. "Playing to Learn: Panelists at Stanford Discussion Say Using Games as an Educational Tool Provides Opportunities for Deeper Learning," 2013.

[5] Hainey, T. "Adopting a Virtual Learning Environment Towards Enhancing Students' Self-efficacy,” 2016.

[6] Foley, E. "7 Benefits And The Powerful Impact Of eLearning In 2018", 2017. 